\title{
O GERENCIAMENTO DE RESÍDUOS URBANOS \\ E OS CATADORES: PODE UMA ATIVIDADE OCUPACIONAL SOCIAL E CULTURALMENTE EXCLUDENTE GERAR INCLUSÃO SOCIAL?
}

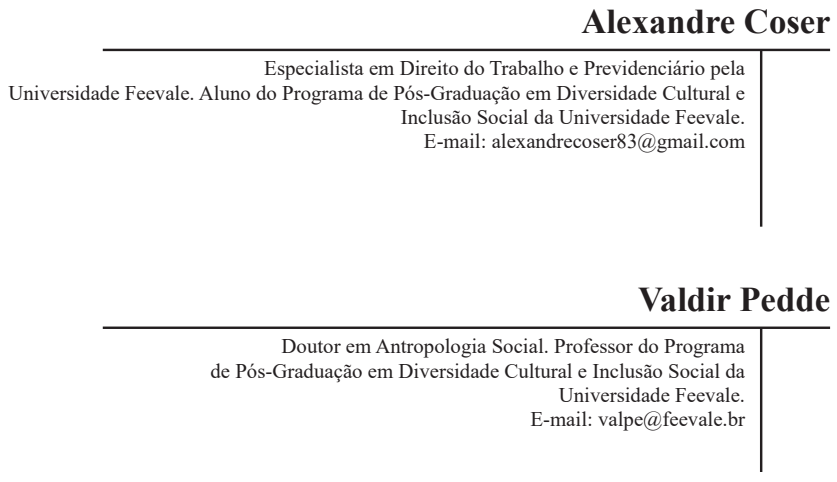

RESUMO

O presente artigo propõe realizar um estudo reflexivo acerca da problemática ambiental dos resíduos e da inclusão social das pessoas que trabalham com materiais recicláveis. Para tanto apresenta-se o seguinte questionamento: "quais as possibilidades de uma atividade ocupacional socialmente excludente gerar inclusão social?". Para tentar responder a pergunta sobre a função integradora que o trabalho deve cumprir na sociedade, este artigo aborda as transformações tecnológicas no mundo do trabalho e seus aspectos na dinâmica da exclusão social, a relevância da problemática ambiental contemporânea, as questões dos resíduos no Brasil após a vigência da Política Nacional de Resíduos Sólidos - Lei 12.305/10, aspectos da condição social dos catadores e os contornos cultuaris inerentes ao contexto brasileiro. O método de pesquisa é o bibliográfico, com abordagem qualitativa. Como objetivo pretende realizar um diálogo reflexivo e aproximativo sobre a temática da inclusão social do catador com aspectos relacionados ao culturalisno, ao reconhecimento social e cidadania.

Palavras-chave: Catadores; Resíduos sólidos; Inclusão/exclusão social. 


\section{THE MANAGEMENT OF URBAN WASTE AND WASTE PICKERS: CAN AN OCCUPATIONAL ACTIVITY SOCIALLY AND CULTURALLY EXCLUDING GENERATE SOCIAL INCLUSION?}

\section{ABSTRACT}

This article presents a reflective study on the environmental problems of waste and the social inclusion of people who labor with recyclable materials. The following question arises: "What are the possibilities of a socially excluding occupational activity to generate social inclusion?" In order to answer the question about the integrative function of labor in society, this article approach the technological transformations in the world of labor and aspects of social exclusion, the relevance of contemporary environmental problems, waste issues in Brazil after the National Solid Waste Policy - Law 12.305/10, aspects of the social condition of the waste pickers and the culturally contours inherent to the Brazilian context. The research method is the bibliographical analysis, with qualitative approach. The objective is to conduct a reflexive and approximative dialogue on the theme of social inclusion of the taster with aspects related to culturalism, social recognition and citizenship.

Keywords: Waste pickers; Solid waste; Social inclusion/exclusion. 


\section{INTRODUÇÃO}

O risco de colapso ecológico e o avanço da desigualdade social são sinais eloquentes da crise do mundo globalizado. Segundo assinala Baumam (2005), os resíduos da sociedade capitalista não são somente aqueles resultantes do descarte dos produtos já utilizados e desprovidos de utilidade, mas também o resíduo humano composto pelos excluídos em consequência do modelo contemporâneo das interações sociais.

Em se tratando da relevância ambiental, o aumento dos resíduos sólidos se encontra diretamente ligado ao estilo de vida moderno assentado sobre o eixo produção-consumo. Além disso, outro aspecto é que a quantidade de resíduos está igualmente ligada ao aumento numérico das cidades e ao crescimento destas.

Estima-se que a população urbana mundial se duplicará até 2050, tal conjuntura gerará maiores repercussões ambientais nesses centros metropolitanos, muito provavelmente com a decorrência da insuficiência de serviços básicos como saúde, emprego, segurança alimentar e deteriorização de recursos naturais (Nova Agenda Urbana - ONU - Hábitat III). Todo o esforço pela sustentabilidade ambiental parece pequeno e insignificante perante o tamanho do desafio do adequado tratamento dos resíduos, além disso o aumento da desigualdade social impacta diretamente nos aspectos do desenvolvimento sustentável estabelecidos na Agenda 2030 - ONU (2015).

Em 2002 o Ministério do Trabalho e Emprego - MTE reconheceu a profissão de catador de material reciclável, sendo a atividade oficializada pela Classificação Brasileira de Ocupações - CBO. Conforme refere Miura (2004), após o reconhecimento legal da profissão, todavia, ainda existem problemas pertinentes ao reconhecimento e implementação dos direitos desses trabalhadores à ter condições dignas de trabalho e de vida que transcendam o simples aspecto da sobrevivência.

Conforme aponta Castel (2009), o trabalho assalariado figura como eixo estruturador das relações sociais em termos de configuração da identidade social e de integração comunitária dos indivíduos. Nesse aspecto, o artigo procura refletir sobre a atividade dos catadores de resíduos, a pergunta básica é se essa atividade, mesmo em um país empobrecido e de ampla desigualdade social como o Brasil, pode ser considerada uma atividade inclusiva e se sim, até que ponto. 
Mesmo havendo diferenças entre os catadores que encontramse associados em cooperativas e os que atuam desvinculados, a inclusão social destes trabalhadores reporta ao questionamento sobre quais as possibilidades de uma atividade ocupacional socialmente e culturalmente excludente gerar inclusão social? A metodologia de pesquisa é pautada em revisão bibliográfica, com o diálogo entre diversos teóricos e busca contribuir como estudo reflexivo sobre a temática.

\section{AS TRANSFORMAÇÕES NAS RELAÇÕES DE TRABALHO}

A tecnologia incorporada aos meios de produção/mercado, vem apresentando ao mundo o seu lado perverso: as transformações ocorridas fazem com que seja possível aumentar a produção nas indústrias ao mesmo tempo diminuindo a necessidade de mão de obra.

No mundo moderno e contemporâneo a problemática do trabalho é reconfigurada sob o aspecto das novas formas de manifestação do capitalismo globalizado, que atualmente apresenta seu modo mais agressivo. Cabe considerar que, até pouco tempo atrás, a criação de postos de trabalho era uma responsabilidade coletiva, dos governos e empresas, e essa responsabilidade agora, foi transferida para o indivíduo, como se não houvesse obstáculos de toda ordem sociais e econômicos.

Em se tratando da dinâmica contemporânea, merece destaque a racionalidade político econômica neoliberal, autores como Dardot e Laval (2016), apontam como sendo o conjunto de medidas políticas adotadas em diversos países a partir de 1970 - 1980, que são pautadas na diminuição da participação do Estado como protetor social e agente regulamentador das relações de mercado para o bem estar social. A marca deste contexto é a transferência da racionalidade política especialmente voltada para fomentar a atividade produtiva e/ou investimentos que beneficiem e ampliem a participação concorrencial no mercado.

Em "As metamorfoses da questão social: uma crônica do salário", Castel (2009), situa a problemática da vulnerabilidade social em virtude da erosão dos sistemas de proteção social na sociedade salarial. ${ }^{1}$ As implicações dessas transformações vieram sob a forma de crescente desemprego, aumento das desigualdades sociais, avanço da pobreza e

1 Para Castel (2009, p. 416-417), a sociedade salarial, é aquela em que o trabalho assalariado torna-se o eixo das relações sociais em termos de configuração da identidade cultural simbólica dos indivíduos. O trabalho passa a assegurar um conjunto de direitos e proteções contra os riscos sociais (doença, desemprego, acidentes), além de permitir uma participação ampliada na vida social, através do acesso ao consumo, à educação, ao lazer e a habitação. 
enfraquecimento de instituições representativas de trabalhadores.

Autores como Silva e Oliveira (2009) apontam que as transformações ocorridas no mundo do trabalho afetaram negativamente diversos trabalhadores. As modificações compreendem aspectos como a crise do antigo modelo fordista de produção, com o surgimento de novas formas de gestão que reduz a necessidade de mão-de-obra e/ou possibilitara a transferência das unidades produtivas para locais com custos produtivos menores.

Como paradigma desse contexto, refere Galeano:

A economia mundial exige mercados de consumo em constante expansão para dar saída à sua produção crescente e para que não despenquem suas taxas de lucro, mas, ao mesmo tempo, exige braços e matéria-prima a preços irrisórios para baratear os custos da produção. O mesmo sistema que precisa vender cada vez mais precisa também pagar cada vez menos. (Galeano, 2011, p. 27).

O contexto contemporâneo segundo Sousa Santos (2003), apresenta o predomínio estrutural dos processos de exclusão social. $\mathrm{O}$ autor ressalta a problemática a partir da abordagem na fragmentação da sociedade entre três tipos, a saber: (1) os indivíduos que gozam de acentuadas formas de inclusão social; (2) os que detém mínima expectativa de efetivação dos seus direitos sociais básicos e; (3) os indivíduos que encontram-se na parcela da sociedade com maior nível de exclusão social.

Conforme Rodríguez (2002), duas categorias de indivíduos se expõem na lógica econômica atual os capazes e os incapazes de enfrentar o mundo competitivo da contemporaneidade: os primeiros com alta qualificação profissional obtêm êxito ao alocar-se nos setores modernos da economia; os segundos que possuem pouca ou nenhuma qualificação figuram como aqueles que encontram-se em trabalhos precários, dificilmente conseguem garantir sua subsistência.

Para Martins (2009), o sistema social capitalista possui um processo próprio de exclusão e re-inclusão. A sociedade moderna vem resultando em uma ampla massa de população que possui improváveis chances de ser novamente incluída nos padrões atuais de desenvolvimento, nesse cenário, o curso do caminho da exclusão para inclusão, que deveria ser transitório, vem se tornando cada vez mais num modo de vida permanente.

Denota-se inteligível que a evolução tecnológica vem estabelecendo mudanças na economia e em toda a sociedade, estas 
modificações exigem uma maior necessidade de adaptação dos indivíduos ao mercado de trabalho. Nesse aspecto, os catadores de materiais recicláveis desenvolvem tal atividade devido às profundas dificuldades de inserção no mercado de trabalho, muitas vezes conexas com questões de idade, condição social e a baixa escolaridade. Observa-se que os catadores desempenham suas atividades em condições extremas, sofrem preconceitos e possuem baixo reconhecimento do papel que representam na economia e no meio ambiente.

O Relatório do Instituto de Pesquisas Econômicas Aplicadas - IPEA (2013), acerca das condições sociais dos catadores, aponta que muitos deles exercem a esta atividade em tempo integral por vários anos, alguns desde a infância. $\mathrm{O}$ mencionado relatório aponta que em diversas famílias essa atividade passa a ser seguida de pai para filho, geralmente por falta de melhores opções.

No que tange às questões de escolaridade dos catadores, os dados do IPEA (2013) apontam que 66,7\% iniciaram os estudos, porém não chegaram a concluir a quarta série do ensino fundamental, 16,7\% declaramse analfabetas e apenas $16,7 \%$ chegaram a concluir o ensino médio. A baixa escolaridade pode ser considerado um nítido fator da exclusão social dos catadores de materiais recicláveis, trata-se, por conseguinte, de uma questão importante para o enfrentamento da pobreza e desigualdade, o que evidencia a dificuldade que estas pessoas encontram para se enquadrarem aos requisitos exigidos pelo mercado de trabalho contemporâneo.

De fato, em se tratando das configurações do trabalho, a matriz contemporânea, exige novas habilidades, para além disso exige uma economia emocional, sobretudo, segundo aponta Souza (2015), novas atitudes dos indivíduos que devem estar aptos a incorporar conhecimentos, especialmente para o mercado cada vez mais competitivo do trabalho.

Dada tal configuração de baixo nível de escolaridade, é possível reconhecer a questão social dos catadores de materiais recicláveis, como uma das facetas oriunda do sistema econômico, visto que a maior parte destes trabalhadores em poucas ocasiões consegue ingressar no mercado de trabalho ou ficou desempregada em face das paulatinas mudanças tecnológicas que transcorreram sistema produtivo. 


\section{A PROBLEMÁTICA DO MEIO AMBIENTE NA SOCIEDADE DE RISCO}

Antes do século XX a produção de resíduos decorrentes das atividades antrópicas quase que se resumiam aos resíduos orgânicos de fácil decomposição na natureza. Conforme refere Porto-Gonçalves (2006), com o desenvolvimento industrial e urbanização, não somente a produção de bens, mas a produção dos resíduos foi intensificada e se diversificou.

Nesse aspecto, os apontamentos expostos na Conferência das Nações Unidas sobre o Meio Ambiente Humano (Estocolmo 1972), e no relatório denominado "Nosso Futuro Comum", realizado em 1987 pela Comissão Mundial sobre o Meio Ambiente e Desenvolvimento, apontam que o homem vem se direcionando para um modo de vida pouco compatível com a finitude dos recursos do planeta. De tal modo é assinalado que o meio ambiente foi considerado um elemento para consecução de fins econômicos.

A ampliação da produção e o aumento do consumo figuram como lógica de manutenção do sistema de acumulação. Esse sistema econômico inseriu-se como subjetividade dominante para grande parte da população, segundo destacam autores como Penna (1999), Gatari (2000) e Bauman (2005).

Quanto mais se consome, mais recursos naturais são extraídos, mais poluição e resíduos são gerados. Demonstrando como se trata na vida cotidiana com os resíduos Bauman (2005) destaca:

\footnotetext{
A história em que e com que crescemos não tem interesse no lixo. Segundo essa história, o que interessa é o produto, não o refugo [...] Removemos os dejetos da maneira mais radical e efetiva: tornando-os invisíveis, por não olhá-los, e inimagináveis, por não pensarmos neles. (Bauman, 2005, p. 38).
}

No âmbito das ciências sociais destaca-se as reflexões dos sociólogos Beck (2011) e Giddens (2005), que constroem a analise conceitual a partir da crítica à modernidade. Os teóricos partem do pressuposto de que a sociedade contemporânea, denominada como pósindustrial é uma sociedade de risco.

Nesse aspecto, os mencionados autores referem o fenômeno da transição da Sociedade Industrial clássica para a Sociedade de Risco, descrita como o momento em que a produção de riquezas é acompanhada 
sistematicamente pela produção social de risco. Tal questão envolvese diretamente com a lógica capitalista de acumulação e os impactos ambientais não podem ser controlados pelos sistemas jurídicos do mesmo modo que na sociedade industrial clássica. ${ }^{2}$

Os avanços das tecnologias não foram acompanhados pela capacidade científica capaz de prognosticar de forma precisa a extensão de todos os seus efeitos colaterais. Os efeitos ecológicos adversos que outrora eram restritos geograficamente passaram a ser globais e afetam as condições da vida em todo planeta, segundo assinala Beck (2011).

Conforme refere Porto-Gonçalves (2006), as transformações nos aspectos da industrialização, entre outras feições, significou o estabelecimento alargado do ritmo humano na exploração dos recursos naturais. Para o autor, o relógio do capital (time is Money) paulatinamente passou a comandar as relações antrópicas na desconsideração dos ciclos naturais.

Consequentemente nesse contexto não apenas a vida humana está envolvida na medida em que englobam-se também todas as espécies existentes e que compõe a biosfera. Portanto, está sendo afetada a teia da vida, descrita por Capra (2012), como a mútua relação de todos os elementos da natureza, responsável pela sustentação ecológica da vida.

Nesse aspecto, Diamond (2007), sugere a reflexão:

A seriedade de nossos problemas ambientais é vigorosamente debatida. Seriam os riscos exagerados ou, ao contrário, subestimados? É razoável pensar que, com nossa potente tecnologia moderna, uma população mundial de quase sete bilhões de indivíduos está destruindo o meio ambiente mundial em um ritmo muito mais acelerado do que alguns milhões de pessoas com instrumentos de pedra e madeira já o destruíram localmente no passado. (Diamond, 2007, p. 22).

Além disso, há um gigantesco descompasso entre a efetiva proteção jurídica do meio ambiente referido por Ost (1997), com a seguinte consideração:

Para traçar o limite do permitido e do interdito, instituir responsabilidades, identificar os interessados, determinar campos de aplicação de regras no tempo e no espaço,

\footnotetext{
2 De acordo com Carvalho (2008), o direito passa por enormes dificuldades em responder aos problemas referentes aos novos interesses ambientais, por deter uma estrutura baseada no individualismo, conflituosidade, na programação condicional voltada para o fato já acontecido, entrelaçado a um antropocentrismo restritivo.
} 
o direito tem o costume de se servir de definições com contornos nítidos, critérios estáveis. [...] A ecologia reclama conceitos englobantes e condições evolutivas; o direito responde com critérios fixos e categorias que segmentam o real. A ecologia fala em termos de ecossistema e de biosfera, o direito responde em termos de limites e de fronteiras; uma desenvolve o tempo longo, por vezes extremamente longo, dos seus ciclos naturais, o outro impõe o ritmo curto das previsões humanas. E eis o dilema: ou o direito do ambiente é obra de juristas e não consegue compreender, de forma útil, um dado decididamente complexo e variável; ou a norma é redigida pelo especialista. (Ost, 1997, p. 111).

A maioria das decisões dos agentes, sejam eles ligados ao Estado ou ao Mercado, são dirigidas às vantagens produtivas, nesse aspecto, Beck (2011), pondera sobre a cegueira em relação aos riscos ambientais. $\mathrm{Na}$ medida em que os riscos figuram como industrialmente produzidos eles também são politicamente reflexivos, uma vez que são ocasionados por decisões, frutos das ações/omissões humanas, num contexto de forças produtivas altamente desenvolvidas.

Segundo Douglas e Wildavsky (2012), a percepção do risco é culturalmente construída. Assim, os riscos são definidos, selecionados e hierarquizados culturalmente, os referidos autores assinalam influência da escala de valores sociais e as definições e atitudes perante o risco. Obviamente, podemos acrescentar que muito dessa escala de valores é amplificada e solidificada institucionalmente, sobretudo, se considerado que a escolha dos riscos são submetidos fortemente pelas instituições modernas, quais sejam, o Estado e o Mercado.

Dessa forma, a sociedade contemporânea enfrenta diversos problemas que podem ser decompostas em duas classes básicas, a saber: (i) o esgotamento dos recursos renováveis, uma vez que determinadas fontes materiais foram sendo dissipadas de maneira pouco ordenada desde os primórdios da industrialização, e, (ii) a poluição dos resíduos lançados no meio ambiente, sobretudo, no modo como é realizado o descarte dos materiais oriundos do atual sistema de produção.

Se o cenário permanecer inalterado, isto é, as taxas de urbanização aumentando mais do que os progressos na área ambiental, nos próximos anos, com os resíduos descartados incorretamente sem o adequado tratamento, haverá o aumento das consequências negativas na vida da população. 


\title{
3 A POLÍTICA NACIONAL DOS RESÍDUOS SÓLIDOS NO BRASIL
}

Apesar de a problemática ambiental estar evidenciada desde a metade do século XX, em se tratando do adequado manejo dos resíduos no Brasil o problema ainda é pouco enfrentado em termos de efetividade. Em estudo realizado pelo IPEA (2012), é apontado que apenas 18\% do total de municípios possuem algum sistema de coleta seletiva de resíduos.

Em que pese possa ser verificada no ordenamento jurídico a previsão sobre o manejo dos resíduos disposto na Lei 11445/97 que estabelece diretrizes nacionais para o saneamento básico, de modo especifico, somente em 2010, com a vigência da Lei 12.305/10, foi instituída a Política Nacional dos Resíduos Sólidos, sendo o marco inicial para a normatização dos serviços a serem realizados pelos municípios, obrigando-os a formalizar planos de gestão dos resíduos urbanos para a disposição final adequada, destacando-se também o objetivo de erradicação dos aterros clandestinos conhecidos por lixões, locais em que o descarte é realizado sem qualquer forma de controle sanitário em relação a contaminação do ar, do solo e da água.

Os pontos de partida da Política Nacional de Resíduos Sólidos são, a diferenciação entre resíduos e rejeitos e a constatação dos resíduos sólidos como dotados de valor socioeconômico. Essa definição é o alicerce para a reciclagem e a destinação final adequada.

A destinação final ambientalmente adequada só ocorre depois de esgotadas as possibilidades de reutilização, reciclagem, compostagem, recuperação e aproveitamento energético do resíduo. ${ }^{3}$ A Lei no 12.305/2010 define a correta destinação dos resíduos, em seu artigo $3^{\circ}$, VII, a saber:

\begin{abstract}
destinação final ambientalmente adequada, a destinação de resíduos que inclui a reutilização, a reciclagem, a compostagem, a recuperação e o aproveitamento energético ou outras destinações admitidas pelos órgãos competentes do Sistema Nacional do Meio Ambiente (Sisnama), do Sistema Nacional de Vigilância Sanitária (SNVS) e do Sistema Único de Atenção à Sanidade Agropecuária (Suasa), entre elas a disposição final, observando normas operacionais específicas de modo a evitar danos ou riscos à saúde pública e à segurança e a minimizar os impactos ambientais adversos (Brasil, 2010). ${ }^{4}$
\end{abstract}

3 O rejeito, nos termos do artigo $3^{\circ}, \mathrm{XV}$, da aludida Lei, é o que sobra após esgotadas todas as possibilidades de tratamento e recuperação por processos tecnológicos disponíveis e economicamente viáveis, não apresentam outra possibilidade que não a disposição final ambientalmente adequada".

4 Importa destacar as diferenças entre reciclagem e reutilização. Assim, reciclagem compreende o "processo de transformação dos resíduos sólidos que envolve a alteração de suas propriedades físicas, 
Além disso, a Lei propõe a responsabilidade compartilhada pelo ciclo de vida do produto (Art. $3^{\circ}$, XVII da Lei 12.305/2010) “[...] enquanto conjunto de atribuições individualizadas e encadeadas de fabricantes, importadores, distribuidores e comerciantes, consumidores e titulares dos serviços públicos de limpeza urbana e manejo dos resíduos sólidos". Estes são agora responsáveis pelo recolhimento e pela destinação adequada dos produtos pós-consumo. Espera-se com tal regulamentação a minimização do volume de resíduos sólidos descartados incorretamente e de rejeitos gerados, além da redução de impactos gerados à saúde humana e à qualidade ambiental, todavia não se trata de uma proposta de concretização simples.

Mesmo com a proibição da destinação de resíduos aos lixões prevista no artigo 47 Lei 12.305/10, ainda são três as formas de disposição final de resíduos sólidos realizadas no Brasil: lixões, aterros controlados e aterros sanitários que seriam o adequado, a saber:

Os lixões conforme Milaré (2004), são locais onde são despejados resíduos sólidos diversos (orgânicos e inorgânicos) sem que haja o tratamento adequado do solo, ocasionando a poluição do ar pela emissão de gás metano proveniente da decomposição dos resíduos orgânicos, do solo e dos lençóis freáticos fonte subterrânea de água;

O aterro controlado é um lixão melhorado, onde os resíduos são dispostos em um terreno sem impermeabilização ou precariamente impermeabilizado, não há tratamento adequado do terreno e os resíduos sólidos ali depositados são de diversas origens (domésticos, industriais, hospitalares, etc), dispostos sem qualquer critério, e; Nos aterros sanitários, o solo é impermeabilizado adequadamente conforme especificações técnicas, ${ }^{5}$ recebe tratamento especializado e monitoramento constantes a fim de evitar, o máximo possível, qualquer tipo de poluição e os gases tóxicos produzidos pela decomposição da matéria orgânica são aproveitados como fonte de energia.

Além do objetivo de regular questões ambientais pertinentes ao descarte e a correta destinação dos resíduos, a referida Lei determina o Plano Nacional de Resíduos Sólidos, tendo metas associadas à inclusão

físico-químicas ou biológicas com vistas à transformação em insumos ou novos produtos [...]” (art. $3^{\circ}$,XIV PNRS) e reutilização o "processo de aproveitamento dos resíduos sólidos sem sua transformação biológica, física ou físico-química [...]" (art. 3º XVIII do PNRS)

5 Aterro sanitário é definido como um aterro de resíduos sólidos urbanos, adequado para a recepção de resíduos de origem doméstica, varrição de vias públicas e comércios. Os resíduos industriais devem ser destinados a aterro de resíduos sólidos industriais (enquadrado como classe II quando resíduo não perigoso e classe I quando tratar-se de resíduo perigoso), de acordo com a norma técnica da ABNT $10.004 / 04$. 
social e à emancipação econômica dos catadores de materiais recicláveis (segundo enunciado disposto no artigo 15, inciso V). A Lei 12.305/2010 reconhece ser preciso integrar os catadores na cadeia da reciclagem para promover a cidadania com a inclusão social pela geração de emprego e renda.

A Política Nacional de Resíduos Sólidos foi pensada e construída no âmbito de uma política ambiental com o objetivo de gerar inclusão social junto ao contexto da gestão dos serviços urbanos de limpeza pública, pautados sob o desafio socioeconômico e ambiental de novos padrões de desenvolvimento local. Todavia, para seu funcionamento requer novos modelos de cooperação e parcerias entre o governo e a sociedade que articulem inclusão social, geração de renda e preservação ambiental.

Segundo o Índice de Sustentabilidade da Limpeza Urbana para os Municípios Brasileiros - SELUR (2017), a implementação das metas estipuladas pela Política Nacional dos Resíduos Sólidos tem apresentado consideráveis desafios. Destaca-se o não cumprimento do prazo para extinção dos lixões, previsto para agosto de 2014 e sua prorrogação para o segundo semestre de 2018.

De acordo com o referido Índice de Sustentabilidade da Limpeza Urbana para os Municípios Brasileiros - SELUR (2017), dos 5.568 municípios brasileiros, 3.326 ainda descartam seus resíduos incorretamente, estimativamente por ano $41,3 \%$ dos 79 milhões de toneladas de resíduos produzidos vão para vazadouros a céu aberto.

Decorridos oito anos da vigência da Política Nacional de Resíduos Sólidos, a aplicabilidade ainda não é plenamente efetivada, Além disso, a baixa separação dos materiais por parte da população e a carência de uma gestão de resíduos sólidos domiciliares nos municípios compõe uma problemática proeminente em diversos aspectos sobretudo o ambiental e o social.

Para que a reciclagem seja satisfatória, os sistemas de coleta seletiva devem ser eficientes, com a separação do resíduos por parte da população, o que depende do poder público - gestão responsável pela coleta - e de cada cidadão - responsável por separar seu lixo de maneira adequada.

Segundo o IPEA (2012), além da coleta seletiva que seria a forma ambientalmente apropriada, uma estratégia dos municípios para a reciclagem dos resíduos que vem sendo adotada é a utilização direta de usinas ou estações de triagem sem coleta seletiva. 
Nessa sistemática os resíduos recolhidos pelas empresas de coleta, sem separação na fonte geradora, são encaminhados às unidades de triagem, cuja operação em muitos casos é realizada por associações de recicladores. Nas unidades onde isso ocorre, o resíduo que é coletado de forma tradicional será separado e em momento posterior o que for aproveitável é encaminhado para reciclagem.

O lugar definido para os catadores neste modelo geralmente os limita à condição de triadores, realizam a triagem do material proveniente da coleta em galpões, os catadores que não se adaptam ao trabalho segundo o formato predeterminado pelos gestores não serão incluídos.

O formato de triagem dos resíduos sem separação prévia, apesar de ter uma implementação mais simples que a dos programas de coleta seletiva, apresenta uma baixa eficiência, pois o material recolhido que chega ao ponto de triagem possui alto grau de contaminação. Após a triagem, os rejeitos não recicláveis - muitas vezes materiais não aproveitados por conta da contaminação, ${ }^{6}$ são depositados em contêineres e posteriormente transportados ao aterro sanitário.

De acordo com Wirth e Oliveira (2016) o modo de gestão nem sempre apresenta os resultados sociais almejados. O princípio econômico também influencia nas soluções técnicas para a gestão dos resíduos a partir da necessidade de menores custos, o caminhão compactador, as esteiras de triagem, a triagem mecanizada são soluções para lidar com um grande volume de resíduo ocupando um pequeno número de trabalhadores. Por efeito, a coleta seletiva encontra problemas para se manter e consolidar, pois apresentam necessidades orçamentárias que entram em choque com os interesses econômicos.

Além de causar uma diminuição no aproveitamento do material reciclável por conta da contaminação, com esta forma de gestão dos resíduos, os trabalhadores dos locais de triagem são expostos à inúmeros riscos ocupacionais. Autores como Arantes e Borges (2013), salientam que esses trabalhadores estão expostos a diversos riscos, dentre eles cortes, perfurações e queimaduras, além de exposição à vetores biológicos. Para

6 Quando não existe separação nas residências, comércios etc., os sacos de lixo coletados na coleta convencional são encaminhados para a triagem, onde os resíduos recicláveis são separados dos orgânicos. Neste caso a separação é muito mais difícil porque os resíduos estão misturados, dificultando a desagregação e comprometendo a qualidade destes. Papel e papelão, presentes em grande quantidade nos resíduos sólidos urbanos, são quase sempre perdidos por estarem contaminados de resíduos orgânicos. Para que qualquer tratamento de resíduos sólidos tenha êxito, é necessário separar o mesmo considerando suas características físico-químicas, além disso, quanto mais bem separado esses resíduos, maior o seu valor agregado para venda. 
os autores, é possível identificar que os sujeitos que trabalham nessa atividade muitas vezes desconhecem os riscos de adoecimento, apesar de manusearem material contaminante, sendo tal circunstancia uma das feições que igualmente devem ser consideradas nos aspectos da inclusão social destes trabalhadores.

Outrossim cabe considerar a remuneração dos trabalhadores dos sistemas de triagem é proveniente da venda do material reciclável, quanto melhor for realizada a separação mais favorável será o resultado da venda do material. Segundo Wirth e Oliveira (2016), esse modelo de gestão também alimenta a disputa com os catadores de fora, uma vez que cria uma cisão entre coleta formal e informal, que de acordo com essa lógica, desviam o material do sistema oficial de coleta.

Conforme sinteticamente aqui exposto, a gestão dos resíduos sólidos constitui uma problemática complexa que envolve aspectos de cunho ambiental, administrativo/econômico, cultural e social. Não obstante a Política Nacional de Resíduos Sólidos trazer prescrições que incorporam o paradigma ambiental, cabe indagar até que ponto a sociedade conseguirá incorporar as mudanças práticas necessárias, já que, além de a legislação ser recente, o modelo historicamente predominante é o do consumo crescente e da não preocupação com a geração dos resíduos.

\section{A CONDIÇÃO SOCIAL DOS CATADORES}

A temática sobre os Catadores de Materiais Recicláveis é desafiadora por envolver indagações que vão além da abordagem clássica de desemprego estrutural e conjuntural por ser um problema multifacetado sobretudo envolvendo a não efetivação dos direitos sociais destes indivíduos e de sua cidadania.

No Brasil os direitos sociais desenvolveram-se tardiamente e o capitalismo do país, conforme Oliven (1982), não é capaz de incorporar ao sistema produtivo toda a população em idade de trabalho. Dessa forma, com a consideração das transformações no mundo do trabalho anteriormente explicitadas, pode-se entender que é expressivo o número de trabalhadores que se encontram sob condições que configuram exclusão social.

A exclusão social trata-se de um conjunto de fenômenos sociais interligados, como o desemprego, a marginalidade, a discriminação, a pobreza, a perda de identidade social e a fragilização dos laços sociais. Nesse aspecto, os indivíduos que sobrevivem da separação dos resíduos 
encontram-se trabalhando nas condições mais adversas e precárias possíveis, sem respaldo jurídico, trabalhista ou assistencial. Sobre as feições da realidade dos catadores Bhowmik (2002) discorre:

A estas pessoas é atribuído o status mais baixo entre os pobres urbanos e economicamente são os mais pobres entre os pobres. Muitos destes coletores de lixo são mulheres e crianças. Eles vagam pelas ruas a pé, procurando lixo, que colocam dentro dos sacos que transportam. Deixam suas casas ao amanhecer, andando vários quilômetros todos os dias, completando ao fim da tarde. Seus instrumentos de trabalho são um saco para a coleta e uma vara para espetar e remexer o lixo. No trabalho, correm vários riscos: ficam com cortes e ferimentos produzidos por objetos cortantes e pedaços de vidro, ou contraem, no lixo, alergias de pele causadas por lixo químico. Depois de terminada a coleta do dia, os coletores separam os materiais, vendidos aos comerciantes. O que recebem como pagamento pela coleta é muito pouco, vivendo estas pessoas no limite da pobreza. (Bhowmik, 2002, p. 375).

Muitas vezes a exclusão destas pessoas compreende um processo dinâmico de desintegração social em que há uma situação de privação na qual os indivíduos são levados à margem das diversas relações econômicas, sociais, políticas e culturais, situação que abarca também o compartilhamento de um estado de pobreza, de discriminação, de subalternidade, de não equidade, de não efetivação dos direitos sociais.

Os dados estimativos do Ministério do Meio Ambiente realizados pelo IPEA (2013), apontam que no Brasil um total aproximado de 400 a 600 mil pessoas realizam a atividade de catadores, deste total, cerca de $10 \%$ atuam associados à cooperativas. Apesar do considerável número de trabalhadores, trata-se de uma classe com articulação incipiente e frágil, que muito recentemente começa lentamente a adquirir notoriedade ante a sociedade e ao poder público, dada a emergência das questões de cunho ambiental.

Uma superficial análise da população de catadores de materiais recicláveis que avalia estes indivíduos como socialmente incluídos por estarem de alguma forma alocados no processo produtivo, induz a uma conclusão equivocada: a de que estas pessoas se encontrariam incluídas por estarem trabalhando. A apreciação da inclusão social dos catadores de materiais recicláveis somente sob o ponto de vista econômico/renda, exibe profundas inconsistências, pois não aprecia todos os aspectos materiais e culturais que se apresentam. 
Alguns pontos na rotina dos catadores são expostos por Martins e Faccenda (2016), a saber: (a) baixo valor pago pelos materiais; (b) rentabilidade insignificante em coletar determinados tipos de materiais; (c) péssimas condições da disponibilização dos materiais por parte da população urbana; (d) dificuldade de transitar pelo município devido ao transito nas ruas com alto fluxo de carros (e) divergências e atritos entre os catadores, como no caso de alguns dispersarem resíduos nas vias, denegrindo a imagem da classe; (f) baixa aceitação social da classe; (g) baixa escolaridade; (h) presença de crianças e mulheres gestantes auxiliando nos trabalhos; (i) jornadas médias de $8 \mathrm{~h}$ em 6 dias por semana; e (j) longos trajetos carregando peso, com distâncias diárias percorridas de até $12 \mathrm{~km}$.

Diante do exposto, é possível constatar que a problemática da inclusão social dos catadores vai muito além de se ter uma ocupação que possibilite uma fonte de renda e subsistência, pois a estas pessoas os direitos sociais são distantes. Estes indivíduos deparam-se com severas situações de precarização ocupacional exercendo uma atividade extenuante, e, por diversas vezes apresentando situações insalubres.

\section{OS ASPECTOS CULTURAIS}

Historicamente, as pessoas empregadas nas práticas e serviços ligados à remoção de resíduos se enquadram na categoria de excluídos sociais. As pessoas que trabalham nestas atividades são discriminadas e consideradas cidadãos de terceira categoria, de acordo com Bauman (2005), eles se encaixam no grupo de pessoas classificadas como refugo humano, os excessivos e redundantes.

A maior parte dos catadores em poucas ocasiões consegue ingressar no mercado de trabalho ou ficou desempregada em face das modificações tecnológicas que transcorreram sistema produtivo. A desigualdade de condições ocasionam situações estigmatizantes, tais como o da culpabilidade pela sua própria exclusão e da vergonha, elementos descritos nos estudos de Miura (2004).

Os catadores de materiais recicláveis, conforme aponta Rodrigues (1999), têm suas identidades traçadas por representações ligadas à pobreza, exclusão e a violência, o que fomenta as discriminações e diminui suas possibilidades e oportunidades na vida destas pessoas.

Estas pessoas, em sua maioria, exercerem a atividade de catar 
materiais recicláveis como a única opção disponível para a sobrevivência Além disso há o elemento subjetivo socialmente compartilhado que para Goffman (1988), concebe tais pessoas como se elas tivessem sido incapazes de aproveitar as oportunidades disponíveis para o progresso nos diversos caminhos consagrados pela sociedade.

Muitas vezes estes sujeitos são vistos como indolentes. Sobre os aspectos culturais, de acordo com Sousa (2015), existe uma racionalidade que opõe e destaca qualitativa e substancialmente as pessoas ditas como "dignas", ou seja, aquelas disciplinadas para o trabalho - com capacidade de autocontrole, prospecção e capacidade de concentração, separadas das pessoas desprovidas de dignidade - que em seu oposto não apresentam estas características. Por efeito, segundo a racionalidade dominante capitalista, aqueles indivíduos que não incorporam tais preceitos valorativos - capital cultural, são desprovidos de importância social.

Segundo leciona Souza (2015), a sociedade é configurada em grupos sociais com acesso não igualitário às disposições para concorrer em equidade, dentre elas o aparelhamento familiar, o capital econômico, o capital social, para incorporar e assimilar o comportamento prático através da educação implícita e explícita. Segundo o autor, tal circunstância apresenta que as pessoas que integram as classes sociais mais elevadas possuem maiores chances de adquirir os requisitos necessários para competir no mercado de trabalho, enquanto os desprovidos tendem a se tornar força braçal.

De tal modo, Souza (2015) chama a atenção para a formação de uma ralé: seres humanos dispensáveis ao sistema, nesta lógica se encontram os catadores de materiais recicláveis. Além disso, Souza (2015) refere que uma das principais causas da exclusão social apresenta-se sobretudo na subjetividade da meritocracia, que se confirma através de uma "violência simbólica" explicada como a exclusão social subjetivamente compartilhada, em razão da consideração da ausência de disciplina para o trabalho como caráter destas pessoas. Nessa feição, é possível perceber como as principais instituições da sociedade se encontram revestidos de valores avaliativos, que influenciam na significação de dignidade e no reconhecimento.

Para Souza (2015), o "capital cultural" é resultante da apropriação do conhecimento útil e altamente valorizado, como capacidade de pensamento abstrato técnico ou literário, conhecimento de línguas, socialização que ajuda na produção de relações pessoais vantajosas. Os 
desprovidos na busca pela sobrevivência diária não desfrutam de idênticas condições para adquirir tal capital.

A subjetividade contida no modelo meritocrático de pensamento compreende que todos os indivíduos partem do mesmo ponto situacional, este posicionamento interpretativo desconsidera os demais aspectos que impedem a competição social em igualdade. Nessa lógica o excluído é percebido como se fosse alguém que possui igualdade de condições, e que se socialmente se desloca do mesmo ponto de partida, com idênticas possibilidades materiais, sendo o sucesso ou fracaço avaliado erroneamente.

Tal feição não avalia, por exemplo, a situação econômica ou familiar da pessoa como fator de aparelhamento a influir na possibilidade de adquirir maior qualificação profissional, visto que, maior capital econômico resultará em maior possibilidade de adquirir qualificação. Nesse aspecto, a sociedade em seu senso comum tende considerar os catadores como desprovidos de dignidade.

Estas aparências em termos de subjetividade social para Souza (2015), refletem na descontinuidade ou inconsistência de políticas públicas redistributivas que visem estabelecer equidade, eis que o discurso culturalmente predominante aponta que "são os novos preguiçosos, que, por culpa própria, escolheram a humilhação e a vida indigna." (Souza 2015, p. 214).

Essas representações subjetivas não são resultados apenas de construções individuais, mas são também construções culturais que originam os estereótipos do desprovido de dignidade na sociedade meritocrática. Pode-se supor que, mesmo com o referido marco normativo da Política Nacional de Resíduos Sólidos - Lei 12.305/10, o catador de material reciclável continua estigmatizado, por não se enquadrar ao padrão profissional pré-estabelecido pela sociedade, nos contornos teóricos descritos por Goffman (1988) e Rodrigues (1999).

Além disso, o senso comum que tende a relacionar a pobreza com a violência. Conforme menciona Oliven (1982): "é revelador que, no Brasil, o termo marginal se refira simultaneamente à mão-de-obra não integrada ao processo de produção capitalista" (Oliven, 1982, p. 11).

Aos excluídos, desprovidos de capital econômico, capital cultural e de dignidade, aqui nos termos de Souza (2015), como amplitudes de capitais conexas às oportunidades de trabalho melhor remunerado, são expostas duas possibilidades: (a) ter de se sujeitar aos ditames do mercado, na condição de pobres honestos, reduzidos à energia muscular, vendendo 
sua força de trabalho muitas vezes por insignificante contraprestação, ou; (b) rebelar-se contra a estrutura que os coloca em tal categoria social, na condição de delinquentes, nas atividades do crime, no tráfico de drogas, prostituição entre outras.

Diante dos contornos aqui apresentados, pertinente a reflexão/ questionamento: Como esperar que os desprovidos que a própria sociedade acaba excluindo (em consequência dos mecanismos econômicos e da maneira com que tais mecanismos agem normalmente, criando desemprego e desigualdade), sintam lealdade pelas instituições e obedeçam às regras jurídicas que sancionam sua exclusão?

O senso comum proclama que a atividade do catador de materiais recicláveis constitui uma possibilidade de inclusão social. Diante de tais perspectivas, cabe questionar sobre qual modo e qualidade se dá este tipo de inclusão social? Eis que para estes indivíduos e suas famílias, o reconhecimento e as possibilidades de obter a qualificação - o capital cultural exigido pelo mercado de trabalho é praticamente insignificante, o que torna a melhoria das condições sociais dos catadores uma tarefa pouco simples e demandam o enfrentamento das variadas facetas da exclusão social destas pessoas.

\section{CONSIDERAÇÕES FINAIS}

A crises ecológica e social podem ser observadas como sintoma perverso emergente da cultura ocidental e do modo como se operam as relações sociais no capitalismo. O presente estudo procurou visualizar reflexivamente alguns dos pontos inerentes à problemática social ${ }^{7} \mathrm{e}$ ambiental ${ }^{8}$ do contexto contemporâneo, nesse aspecto, o enfrentamento de tais questões torna-se urgente.

Os catadores em sua grande maioria possuem um histórico de trabalho precário no que toca os direitos laborais e garantias sociais, circunstância que para ser enfrentada torna imprescindível além do reconhecimento social, o fortalecimento de instituições que garantam

7 Em seu texto legal a Constituição Federal brasileira de 1988, proclama o objetivo de "a erradicação da pobreza, da marginalização, a diminuição das desigualdades sociais e regionais, conforme texto do Artigo $3^{\circ}$ : Constituem objetivos fundamentais da República Federativa do Brasil: I - construir uma sociedade livre, justa e solidária; II - garantir o desenvolvimento nacional; III - erradicar a pobreza e a marginalização e reduzir as desigualdades sociais e regionais; IV - promover o bem de todos, sem preconceitos de origem, raça, sexo, cor, idade e quaisquer outras formas de discriminação.

8 A doutrina jurídica brasileira aponta o direito ao Meio Ambiente sadio como um direito fundamental, tendo em vista que é pressuposto para o respeito e concretização do princípio da dignidade da pessoa humana. 
suportes sociais em termos de proporcionar inclusão social e melhorar a qualidade nas condições de trabalho, acesso à educação, garantias previdenciárias, assistência à saúde, qualificação profissional, etc.

A exclusão social dos catadores de materiais recicláveis é uma problemática que merece ampliação das discussões, no sentido de contribuir para a visibilidade desse segmento social, que demanda por ações que visem transformação de sua realidade, tornando-a mais justa e igualitária.

Notadamente existe, o dever de criar as condições para que estas pessoas possam participar como sujeitos iguais do sistema de cooperação socioeconômica que deveria ser a sociedade, sendo esta uma demanda por justiça social em um país com grandes desigualdades socioeconômicas.

Uma sociedade democrática justa é aquela comprometida com a garantia de direitos básicos iguais e uma parcela equitativa dos recursos - renda, riqueza e oportunidades educacionais e ocupacionais - a todos os seus cidadãos. Nesse aspecto, considerar meramente que o catador ao exercer uma atividade ocupacional que lhe gere subsistência, não significa em sí uma real circunstância de inclusão social como propõe a Lei 12.305/2010.

Existe uma dificuldade muito grande em conscientizar os maiores geradores de lixo domiciliar, pois em sua maioria moram em grandes centros, ou seja bem longe do destino final e os problemas gerados por seu resíduo não estão ao alcance de seus olhos, sendo necessária a mudança dessa cultura. Além disso, a implementação insuficiente de sistemas de coleta seletiva por parte dos municípios além ser ambientalmente negativo, influi diretamente nas condições do trabalhador das estações de triagem, a não separação dos resíduos pode ser igualmente considerada como mais uma forma de violência simbólica.

O reconhecimento social, conforme leciona Taylor (1994), é fator importante para o enfrentamento da invisibilidade social - obstáculo à igualdade de direitos e construção da cidadania. A inclusão dos catadores demanda em diversos níveis o reconhecimento da importância destes para o sistema social, sobretudo no modo como estes são considerados em termos do direcionamento das políticas públicas e de subjetividade social para com o catador.

Denota-se necessário o fortalecimento da cidadania destes indivíduos porém tal fortalecimento não se revela como uma resposta simples, pois a estes indivíduos estão ausentes os requisitos mínimos 
para participação na sociedade. Cabe considerar que na medida em que há exclusão social, o excluído é aquele que não exerce sua cidadania e é visto como um subcidadão, sendo incapaz de reagir à sua realidade perante as instituições, estando assim preso em condições de vida por vezes subumanas e distantes do ideal de dignidade. ${ }^{9}$

Mesmo com o avanço legislativo ocasionado pela a Lei $\mathrm{n}^{\circ}$. 12.305/2010, destaca-se ainda a baixa adoção da separação dos materiais por parte da população se comparado ao volume que é produzido; a insuficiência da política para inclusão de catadores avulsos; a ausência de remuneração adequada pelos serviços prestados entre outros aspectos.

Convém refletir que com a Política Nacional de Resíduos Sólidos um passo foi dado, no sentido de abrir espaço às cooperativas. Mas, e quanto aos catadores individuais? Pela Lei, para inserir-se nos projetos de inclusão, os catadores devem participar das cooperativas ou associações, muitos não conseguem participar pelos mais diversos motivos, de modo que é questionável tal inclusão social por apresentar caráter excludente.

Diante do que aqui foi apresentado, insta questionar quais as possibilidades de uma atividade ocupacional socialmente e culturalmente excludente gerar inclusão social? Uma vez que acima das configurações aparentes de inclusão social, podem coexistir demais formas exclusão.

A resposta à indagação do título do presente texto não foi respondida, ainda há significativas melhorias a serem implementadas tanto no modo de descarte dos resíduos como na viabilização da inclusão social pelo trabalho, restando, inclusive aberto o questionamento se à medida que as preocupações com o meio ambiente ganham espaço, ocorrerá um reconhecimento crescente dos catadores por parte da sociedade?

$\mathrm{O}$ presente estudo não esgota o assunto, procura evidenciar a complexidade do tema que tratam aspectos ambientais dos resíduos e a inclusão social do catador de materiais recicláveis diante do contexto contemporâneo.

\footnotetext{
9 Dentro dessa linha de pensamento, há de se reconhecer que o conjunto de direitos existenciais que compõem a dignidade pertence aos homens em igual proporção, Sarlet (2002, p.60), analiticamente, define a dignidade da pessoa humana como: a qualidade intrínseca e distintiva de cada ser humano que o faz merecedor do mesmo respeito e consideração por parte do Estado e da comunidade, implicando, neste sentido, um complexo de direitos e deveres fundamentais que assegurem a pessoa tanto contra todo e qualquer ato de cunho degradante e desumano, como venham a lhe garantir as condições existenciais mínimas para uma vida saudável, além de propiciar e promover sua participação ativa e co-responsável nos destinos da própria existência e da vida em comunhão com os demais seres humanos.
} 


\section{REFERÊNCIAS}

ABNT - ASSOCIAÇÃO BRASILEIRA DE NORMAS TÉCNICAS. NBR 10004: Resíduos sólidos - classificação. Rio de Janeiro, 2004.

ANTUNES, Ricardo. Os sentidos do trabalho: ensaio sobre a afirmação e a negação do trabalho. 6. ed. São Paulo: Boitempo, 2002.

ARANTES, Bruno Otávio; BORGES, Livia de Oliveira. Catadores de materiais recicláveis: cadeia produtiva e precariedade. Arq. Bras. Psicol., Rio de Janeiro, v. 65, n. 3, p. 319-337, 2013. Disponível em: <http://pepsic.bvsalud.org/scielo.php?script=sci_arttext\&pid=S1809-52672013000300002>. Acesso em: 10 jul. 2018.

BAUMAN, Zygmunt. Vidas desperdiçadas. Rio de Janeiro: Jorge Zahar, 2005.

BECK, Ulrich. Sociedade de risco: rumo a uma outra modernidade. São Paulo: Editora 34, 2011.

BRASIL. Constituição da República Federativa do Brasil de 1988. Disponível em: <http://www.planalto.gov.br/ccivil_03/constituicao/ constituicao.htm>. Acesso em: 15 out. 2017.

BRASIL. Lei n. 11.445, de 5 de janeiro de 2007. Estabelece as diretrizes nacionais para o saneamento básico, cria o Comitê Interministerial de Saneamento Básico, altera a Lei n. 6.766, de 19 de dezembro de 1979, a Lei n. 8.036, de 11 de maio de 1990, a Lei n. 8.666, de 21 de junho de 1993, e a Lei n. 8.987, de 13 de fevereiro de 1995, e revoga a Lei n. 6.528, de 11 de maio de 1978. Coletânea de legislação e jurisprudência, Brasília. Legislação Federal e marginalia. Disponível em: <http://www.planalto.gov.br/ ccivil_03/_ato2007-2010/2010/1ei/112305.htm>. Acesso em: 15 out. 2017.

BRASIL. Lei n. 12.305, de 2 de agosto de 2010. Institui a política nacional de resíduos sólidos; altera a Lei n. 9.605, de 12 de fevereiro de 1998; e dá outras providências. Coletânea de legislação e jurisprudência, Brasília. Legislação Federal e marginalia. Disponível em: <http://www.planalto.gov. br/ccivil_03/_ato2007-2010/2010/lei/112305.htm>. Acesso em: 15 out. 2017.

BHOWMIK, Sharit. As cooperativas e a emancipação dos marginalizados: estudos de caso de duas cidades na Índia. In: SINGER, Paul et al. Produzir para viver: os caminhos da produção não capitalista. Rio de Janeiro: Civilização Brasileira, 2002. 
CASTEL, Robert. As metamorfoses da questão social: uma crônica do salário. Petrópolis: Vozes, 2009.

CAPRA, Fritjof. A teia da vida: uma nova compreensão científica dos sistemas vivos. 13. ed. São Paulo: Cultrix, 2012.

CARVALHO, Delton Winter de. Dano ambiental futuro: a responsabilização civil pelo dano ambiental. Rio de Janeiro: Forense Universitária. 2008.

COMISSÃO MUNDIAL SOBRE MEIO AMBIENTE E DESENVOLVIMENTO. Nosso futuro comum. 2. ed. Rio de Janeiro: Fundação Getúlio Vargas, 1991.

DARDOT, Pierre; LAVAL, Cristian. A nova razão do mundo: ensaio sobre a sociedade neoliberal. São Paulo: Boitempo, 2016.

DIAMOND, Jared M. Colapso: como as sociedades escolhem o fracasso ou o sucesso. Rio de Janeiro: Record, 2007.

GALEANO, Eduardo. De pernas pro ar: a escola do mundo ao avesso. Porto Alegre. L\&PM. 2011.

GOFFMAN, Erving. Estigma: notas sobre a manipulação da identidade deteriorada. 4. ed. São Paulo: LTC, 1988.

GIDDENS, Anthony. Sociologia. 4. ed. Porto Alegre: Artmed, 2005.

IPEA - INSTITUTO DE PESQUISA ECONÔMICA APLICADA. Diagnóstico dos resíduos sólidos urbanos. Brasília, 2012. Disponível em: $<$ http://www.ipea.gov.br/agencia/images/stories/PDFs/relatoriopesquisa/121009_relatorio_residuos_solidos_urbanos.pdf $>$. Acesso em: 25 out. 2017.

IPEA - INSTITUTO DE PESQUISA ECONÔMICA APLICADA. Situação social dos catadores e catadoras de material reciclável e reutilizável. Brasília, 2013. Disponível em: <http:/www.ipea.gov.br/agencia/images/ stories/PDFs/situacao_social/131219_relatorio_situacaosocial_mat_reciclavel_brasil.pdf $>$. Acesso em: 25 out. 2017.

MARTINS, José de Souza. Exclusão social e a nova desigualdade. 4. ed. São Paulo: Paulus, 2009.

MARTINS, Ricardo Rodrigo de Oliveira; FACCENDA, Henrique Baldi. Forum Internacional de Resíduos Sólidos. Comparação dos agentes Selecionadores de Materiais Recicláveis em Santa Maria - RS. Anais do $7^{\circ}$ Forum Internacional de Resíduos Sólidos. Jun. 2016. Disponível em: 
$<$ http://www.institutoventuri.org.br/ojs/index.php/firs/article/view/16/12> . Acesso em: 4 out 2017.

MILARÉ, Édis. Direito do ambiente: Doutrina - Jurisprudência Glossário. 3. ed. São Paulo: Revista dos Tribunais, 2004.

MIURA, Paula Orchiucci Cerantola. Tornar-se catador: uma análise psicossocial. Dissertação (Mestrado em Psicologia Social) - Pontífica Universidade Católica de São Paulo, São Paulo, 2004. Disponível em: $\quad<$ http://www.sapientia.pucsp.br/tde_arquivos/25/TDE-2009-0909T13:34:15Z-8342/Publico/Paula\%20Miura\%20completa.pdf $>$. Acesso em: 12 jun. 2018.

NAÇÕES UNIDAS NO BRASIL - ONU BR. A agenda 2030. Disponível em: < https://nacoesunidas.org/pos2015/agenda2030/>. Acesso em: 13 mar. 2016.

OLIVEN, Ruben G. As vítimas da violência no Brasil. In: Violência e cultura no Brasil. Petrópolis: Vozes, 1982.

ORGANIZAÇÃO DAS NAÇÕES UNIDAS. Habitat III: nova agenda urbana. Disponível em: $<$ https:/habitat3.org/about $>$. Acesso em: 24 mar. 2018 .

OST, François. A natureza à margem da lei: a ecologia à prova do direito. Lisboa: Instituto Piaget, 1997.

PENNA, Carlos Gabaglia. O estado do planeta: sociedade de consumo e degradação ambiental. Rio de Janeiro; São Paulo: Record, 1999.

PORTO-GONÇALVES, Carlos Walter. A globalização da natureza e a natureza da globalização. 2. ed. Rio de Janeiro: Civilização Brasileira, 2006.

RODRIGUES, José Carlos. O corpo na história. Rio de Janeiro: Fiocruz, 1999.

RODÍGUEZ, César. À procura de alternativas econômicas em tempos de globalização: o caso das cooperativas de recicladores de lixo na Colômbia. In: SINGER, Paul et al. Produzir para viver: os caminhos da produção não capitalista. Rio de Janeiro: Civilização Brasileira, 2002.

SARLET, Ingo Wolfgang. Dignidade da pessoa humana e direitos fundamentais na Constituição Federal de 1988. Porto Alegre: Livraria do Advogado, 2002. 
SILVA, Marcelo Kunrath; OLIVEIRA, Gerson de Lima. Solidariedade assimétrica: capital social, hierarquia e êxito em um empreendimento de “economia solidária”. Rev. Katálysis, Florianópolis, v. 12, n. 1, p. 59-67, jun. 2009. Disponível em: $<$ http://www.scielo.br/scielo.php?script=sci_arttext\&pid=S1414-49802009000100008>. Acesso em: 29 dez. 2017.

SELUR - SINDICATO DAS EMPRESAS DE LIMPEZA URBANA. Índice de sustentabilidade da limpeza urbana para os municípios brasileiros. 2. ed. São Paulo: PwC Brasil, 2017. Disponível em: $<$ https:// www.selur.com.br/wordpress/wp-content/uploads/2017/08/ISLU_2EDICAO_2017.pdf>. Acesso em: 10 jul. 2017.

SOUZA, Jesse. A tolice da inteligência brasileira: ou como o país se deixa manipular pela elite. São Paulo: Leya, 2015.

SOUSA SANTOS, Boaventura de. Poderá o direito ser emancipatório. Revista Crítica de Ciências Sociais, n. 65, p. 3-76, maio 2003. Disponível em: $<$ http://www.boaventuradesousasantos.pt/media/pdfs/podera_o_direito_ser_emancipatorio_RCCS65.PDF>. Acesso em: 25 out. 2017.

TAYLOR, Charles. Multiculturalismo: examinando a política de reconhecimento. Lisboa: Instituto Piaget, 1994.

WIRTH, Ioli Gewehr; OLIVEIRA, Cristiano Benites. A Política Nacional de Resíduos Sólidos e os modelos de gestão. In PEREIRA, Bruna Cristina Jaquetto; GOES, Fernanda Lira. (Orgs.). Catadores de materiais recicláveis: um encontro nacional. Brasília: Ipea, 2016. Disponível em: $<\mathrm{http}: / /$ www.ipea.gov.br/portal/images/stories/PDFs/livros/livros/160331_livro_ catadores.pdf>. Acesso em: 20 abr. 2018.

Artigo recebido em: 20/08/2018. Artigo aceito em: 06/02/2019.

\section{Como citar este artigo (ABNT):}

COSER, A.; PEDDLE, V. O gerenciamento de resíduos urbanos e os catadores: pode uma atividade ocupacional social e culturalmente excludente gerar inclusão social?. Veredas do Direito, Belo Horizonte, v. 16, n. 34, p. 253-277, jan./abr. 2019. Disponível em: $<$ http://www.domhelder.edu.br/ revista/index.php/veredas/article/view/1336>. Acesso em: dia mês. ano. 